\title{
New Insights into Sulfide Inclusions in 1018 Carbon Steels
}

\author{
Nathaniel Rieders ${ }^{1}$, Manjula Nandasiri ${ }^{2}$, David Mogk ${ }^{1}$ and Recep Avci ${ }^{1, *}$ \\ 1 Imaging and Chemical Analysis Laboratory, Physics Department, Montana State University, \\ Bozeman, MT 59717, USA; nathaniel.rieders@montana.edu (N.R.); mogk@montana.edu (D.M.) \\ 2 Arconic Technical Center, New Kensington, PA 15068, USA; Manjula.Nandasiri@arconic.com \\ * Correspondence: avci@montana.edu
}

\section{check for}

updates

Citation: Rieders, N.; Nandasiri, M.; Mogk, D.; Avci, R. New Insights into Sulfide Inclusions in 1018 Carbon Steels. Metals 2021, 11, 428. https:// doi.org/10.3390/met11030428

Academic Editor: Marcello Cabibbo

Received: 15 January 2021

Accepted: 25 February 2021

Published: 5 March 2021

Publisher's Note: MDPI stays neutral with regard to jurisdictional claims in published maps and institutional affiliations.

Copyright: (C) 2021 by the authors. Licensee MDPI, Basel, Switzerland. This article is an open access article distributed under the terms and conditions of the Creative Commons Attribution (CC BY) license (https:// creativecommons.org/licenses/by/ $4.0 /)$.

\begin{abstract}
The role of heterogeneous phases in the localized corrosion of materials is an emerging area of research. This work addresses the detrimental role MnS inclusions play in the localized corrosion of carbon steels. We report the results of surface and bulk characterization of MnS inclusions in 1018 carbon steel, using a high-resolution integrated Auger nanoprobe. It is shown that the surface morphology and composition of the inclusions are highly heterogeneous. MnS inclusions are found to be nonstoichiometric and to contain a highly O-enriched surface layer. Some inclusions are covered with a thin (approximately $5 \mathrm{~nm}$ ) layer of $\mathrm{Cu}_{2} \mathrm{~S}$. The bulk composition of "MnS" inclusions is found to include $5-7 \%$ Fe and $\mathrm{O}$, and these inclusions are believed to occupy $\mathrm{Mn}$ and $\mathrm{S}$ positions within the "MnS" lattice. Interfaces between "MnS" and host ferric grains are highly disordered. We hypothesize that pitting initiates and develops at these interfaces through a galvanic coupling between the strained and the unstrained ferrite grains.
\end{abstract}

Keywords: carbon steel; inclusion; $\mathrm{MnS} ; \mathrm{Cu}_{2} \mathrm{~S}$; $\mathrm{MnO}$; Auger; SEM; pitting; strain

\section{Introduction}

Numerous studies have demonstrated that pitting corrosion in steels is initiated at nonmetallic (sulfide) inclusions [1-9]; however, the exact mechanism behind the initiation and growth of these pits remains controversial [10-13]. It is believed that the pitting corrosion of metal surfaces is initiated via the local breakdown of the passive oxide film on the metal surface [11]. Similarly, it has been reported that locations in the vicinity of inclusions and secondary phases form the sites for pit initiation in carbon steel [14-16]. In earlier work, it was claimed that certain inclusions appear to be more corrosively active than others [17]. This distinction is associated with the presence of a finely dispersed S-containing precipitate in the immediate surrounding of the inclusion, which acts as a source of sulfide ions and in turn catalyzes anodic and cathodic reactions $[17,18]$. It has been claimed that Mn-rich sulfide inclusions are more prone to pitting than inclusions rich in Fe [2]. One proposed model of pit initiation in stainless steels involves the presence of a Cr-depleted region in the near vicinity of an inclusion $[10,11,19]$. This region causes a disruption in the passive layer, and thus pitting is initiated around the inclusion. It has been suggested that $\mathrm{MnS}$ inclusions play different roles in the pitting behavior of carbon and stainless steels [17]: in the case of stainless steels, sulfide inclusions are the sites of anodic activity, whereas in the case of carbon steel, inclusions are the sites of cathodic activity. In another claim, the size and shape of inclusions affect the dissolution kinetics [5,20]. Our past work points to the matrix surrounding an inclusion in carbon steel being highly strained because of its metallurgical preparation, and to this strain initiating the dissolution of $\mathrm{Fe}^{2+}$ ions around the inclusion in a corrosive environment [14,15,21].

MnS inclusions have been categorized into types based on shape, morphology, and chemical composition using optical and scanning electron microscopy (SEM) techniques [22]. Energy-dispersive X-ray spectroscopy (EDX) associated with SEM has been a common tool for obtaining the bulk elemental composition of inclusions. Li and Hihara recently 
used a complementary micro-Raman spectroscopy technique to characterize the inclusions in carbon steel [23]. They were able to identify alumina, calcium aluminates, manganese sulfide, and iron sulfide as the major components of various inclusions.

Two important and necessary analytical capabilities are needed if one wishes to elucidate the relationship between these inclusions and the pitting corrosion of steels. The first is surface sensitivity, as corrosion is a surface phenomenon. The second is nanometer spatial resolution, as the inclusions in question and their immediate vicinities pertain to length scales on the order of nanometers to microns. The traditional method of EDX fails both of these criteria. This is due to the large analytical volume (approximately $1 \mu \mathrm{m}$ ) resulting in poor spatial resolution and surface sensitivity [24]. The $X$ rays generated by the interactions of the high-energy electrons (10-30 keV) probe micron-sized volumes rather than nanometer-sized regions, which is required to assess the localization of elements. In contrast to EDX, Auger electron spectroscopy (AES) can provide quantitative compositional information with a lateral resolution of 10-20 nm, and at depths of only a few atomic layers. The reason for this is that AES focuses on Auger electrons (with kinetic energies between 30 and $3000 \mathrm{eV}$ ), while the primary electrons generate characteristic $X$ rays with energies of about 0.5 to $15 \mathrm{keV}$. The attenuation lengths of $\mathrm{X}$ rays in metals are measured in microns, whereas those of Auger electrons are smaller by three orders of magnitude, or approximately 3-5 nm [24,25]. Complementary crystallographic data on submicron inclusions can be obtained using electron backscatter diffraction (EBSD), which provides phase identification and information pertaining to crystalline structure and order from the same inclusion with submicron spatial resolution. An integrated Auger nanoprobe equipped with SEM, EDX, AES, and EBSD provides a comprehensive characterization of bulk and surface compositional properties, and of crystallographic structure and orientation of inclusions in steel. The Imaging and Chemical Analysis Laboratory (ICAL) at Montana State University is fortunate to have one of these integrated Auger nanoprobe instruments. In the following, we present data obtained with this instrument and provide new insights into sulfide inclusions and their relationship to localized corrosion in 1018 carbon steels. Shown in Figure 1 are just a few examples of the various inclusions observed on 1018 carbon steel, which contains a myriad of defects and secondary phases, and this article focuses on the so-called "MnS" inclusions as the sites for pit initiation and growth as articulated below. The fact that pits are empirically known to be initiated proximal to secondary phases is to be expected, as the interface between the bulk steel and secondary phases is likely to be disordered, highly heterogeneous, and strained. To date, however, a careful consideration of the chemical composition and the respective spatial distributions of sulfide grains within and adjacent to the host metal is lacking. Similarly, very little attention has been given to the surface composition, the degree of atomic ordering in the crystalline structure, and the crystallographic orientation within inclusions. Moreover, significantly more attention has been given in the literature to an understanding of the role of inclusions in the localized corrosion of stainless steels, despite the widespread use of carbon steel as a structural material in modern society. In short, a complete physical and chemical picture of nonmetallic inclusions in low-carbon steels is lacking [26]. This has contributed to the continued controversy concerning pitting corrosion and to a lack of understanding of the relevant properties of inclusions in these alloys in relation to the processes of localized corrosion. A comprehensive analysis and understanding of these inclusions, and their respective interfaces with the host metal, is necessary to demonstrate the relationship between the initiation/growth of pits, and the properties of the local host material at the nanometer scale. 

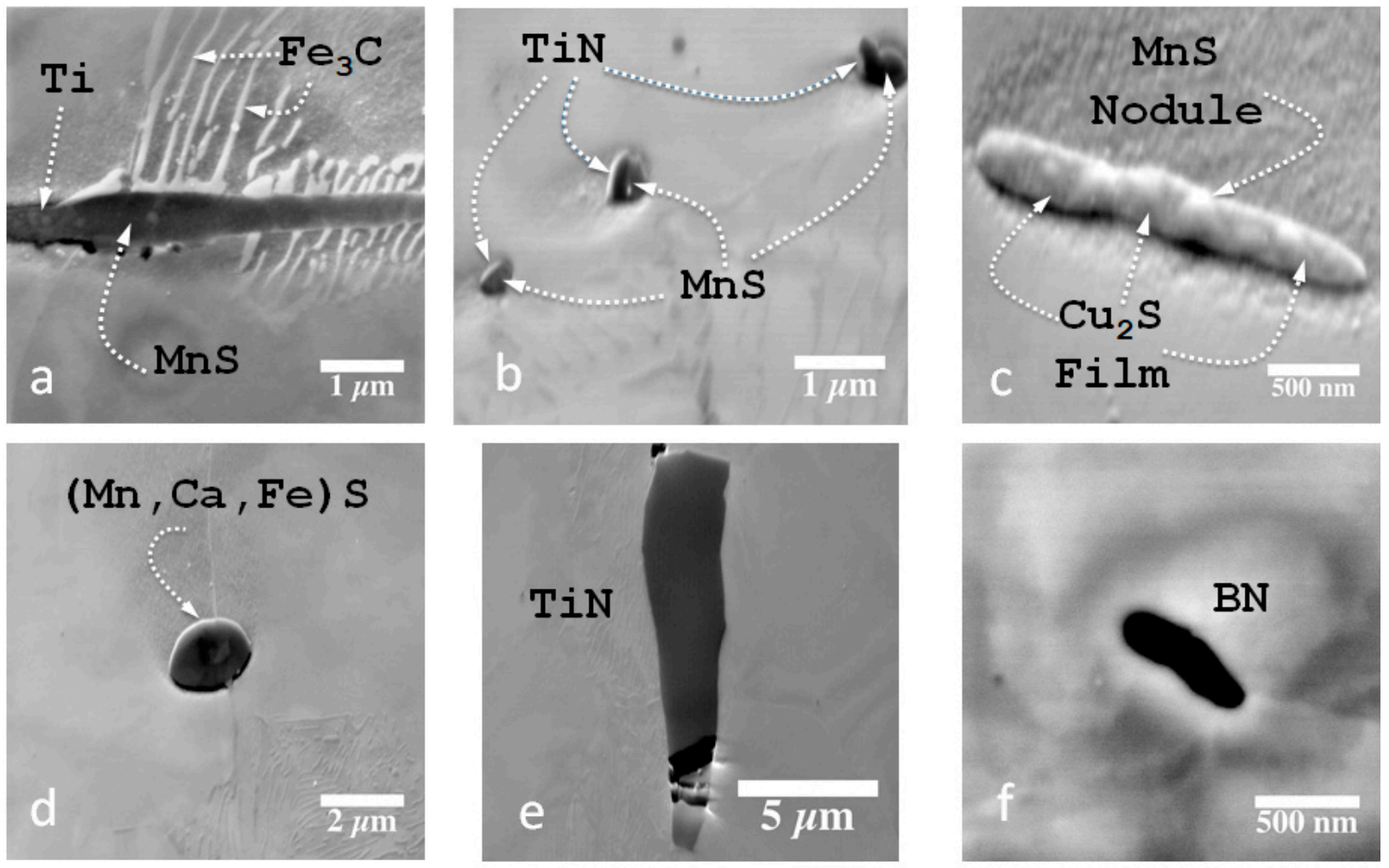

Figure 1. SEM images of a variety of inclusions found in 1018 carbon steel. Data were acquired using an integrated Auger nanoprobe. (a) MnS inclusion cut parallel to the rolling direction during the steel production process. A Ti-containing phase (believed to be TiS) was found at the tip of the inclusion. (b) MnS and TiN duplex inclusions. (c) MnS inclusion with a thin $\mathrm{Cu} 2 \mathrm{~S}$ film. Mn-rich nodules are observed, which do not contain a Cu2S film. (d) A (Mn,Ca,Fe)S inclusion. (e) A pure single-crystal TiN inclusion. (f) A BN inclusion.

\section{Experimental Procedure}

Samples of 1018 carbon steel, composed primarily of the phase ferrite ( $\alpha$-Fe with BCC structure), were purchased as bars from NESSteel, Inc.(Tolland, CT, USA) The elemental composition of 1018 carbon steel, in wt. \%, is $0.14-0.16 \mathrm{C}, 0.6-0.9 \mathrm{Mn}$, less than $0.004 \mathrm{P}$, less than $0.05 \mathrm{~S}$, and the balance Fe. These bars were then cut either parallel or perpendicular to the rolling direction of the steel to produce approximately $1 \times 1 \mathrm{~cm}^{2}$ coupons. The coupons were mounted on glass microscope slides using silicone glue and subsequently polished with silicon carbide polishing paper up to 1200 grit $(2.5 \mu \mathrm{m})$, followed by a diamond slurry down to a smallest particle size of $0.1 \mu \mathrm{m}$. The samples were then rinsed with ultrapure deionized water and dried with dry nitrogen, unmounted, and cleaned via sonication in acetone. The coupons were then introduced into an integrated PHI 710 Integrated Auger Nanoprobe (Physical Electronics; PHI, Chanhassen, MN, USA). This instrument allows one to obtain compositional information from the bulk EDS, as well as nanometer-scale imaging of textures and morphologies by means of field emission scanning secondary electron microscopy (FE-SEM), surface compositional data from a few atomic layers ( $3-5 \mathrm{~nm} ; \mathrm{AES}$ ), crystal structure and crystallographic orientation (EBSD), and chemical stratigraphy using depth-profiling capabilities ( $\mathrm{Ar}^{+}$-ion sputter gun). In order to increase the surface sensitivity and lateral resolution, a $10 \mathrm{keV}$ electron beam was used for the collection of EDX and AES data. The measured spatial resolution at this accelerating voltage is about $15 \mathrm{~nm}$. Overall image resolution at various primary beam energies was determined using standard gold nanoparticles on a carbon substrate. The image resolution improves down to approximately $5 \mathrm{~nm}$ at an incident electron beam energy of $25 \mathrm{keV}$. To correct for spatial shifts in the electron beam during the collection of Auger data and depth profile analysis, an image registration algorithm (available in PHI's (Physical Electronics; 
PHI, Chanhassen, MN, USA) instrument control software) was used. As is standard practice in the collection of EBSD data, a $20 \mathrm{keV}$ beam was used with the sample tilted to 70 degrees from the horizontal (i.e., electrons entered the surface at an approximate 20 degree grazing angle). Only data points for which the confidence index [27] of the acquired pattern was greater than 0.1 were used. The spatial resolution at this accelerating voltage is estimated to be approximately $8 \mathrm{~nm}$. The floating argon sputtering gun was used to obtain depth profiling and related compositional changes within the surface of the sample down to depths of approximately $60 \mathrm{~nm}$. Ar-ion energies of 500 to $1000 \mathrm{eV}$ were used during depth-profile measurements. An estimate of the sputtering rate was determined via depth profiles of standard $100 \mathrm{~nm} \mathrm{SiO}$ grown on $\mathrm{Si}$ wafers.

\section{Results and Discussion}

Figure 2 shows an SEM image of a typical "MnS" inclusion from a polished 1018 carbon steel sample that was cut parallel to the rolling direction of the steel bar. Auger and EDX survey spectra were taken at locations both on the inclusion and on the steel surface (marked as 1, 2, and 3). The inclusion is not solely composed of Mn and $\mathrm{S}$ but contains other elements such as $\mathrm{Fe}, \mathrm{Cu}$, and $\mathrm{O}$ as observed in the Auger spectra from regions 1 and 2. The Ar peaks observed in regions 1 and 2 of the Auger spectra are a result of light sputtering (approximately $0.5 \mathrm{~nm}$ ) to remove some of the environmental hydrocarbon contaminants typically present on any given surface. It is interesting to note that the Ar signal is only observed on the inclusion, despite the fact that the entire region was sputtered with Ar-ions. The observed C signal is believed to originate from environmental contamination left over after the light sputtering. Cu was observed on the surface of many of the inclusions during this study, and we provide insight into its origin below. The spectrum from region 3 was collected from an area outside the inclusion, in the bulk ferrite phase. Evidence of a small $\mathrm{Cu}-L$ series X-ray peak is observed in the EDX spectrum, but not in the Auger spectrum. Its presence is likely related to the poor lateral resolution of EDX relative to AES and likely originates from the inclusion.

Auger elemental maps and cross-sectional elemental line profiles of the inclusion (a SEM image of which is shown at the top of Figure 2) are shown in Figure 3. Regions that are relatively enriched in Mn can be observed on the right side of the inclusion. This enrichment is not observed in the S map, demonstrating that $\mathrm{Mn}$ and $\mathrm{S}$ are not spatially correlated everywhere. Upon closer inspection of the SEM image (Figure 2), a nodular morphology appears to be associated with these Mn-rich regions. Similar Mn-rich nodules are also observed along the inclusion. A cross-sectional line scan across one such nodule is shown in Figure 3 (Line Profile 1). The Mn signal is shifted toward the right side of the inclusion relative to the $\mathrm{S}, \mathrm{Fe}$, and $\mathrm{O}$ profiles. We also note that the $\mathrm{Fe}$ profile is asymmetric, with a larger concentration gradient (slope) on the right of the inclusion than on the left. Considering the surface sensitivity of the Auger electrons, these observations suggest that the chemical composition of the nodule is different from that of the bulk inclusion, specifically that the nodule is more akin to a metal oxide than to a metal sulfide. Line Profile 2 (Figure 3) does not pass over such a nodule. Here, the Fe, Mn, S, and O signals are somewhat spatially correlated to one another, and the type of segregation between the Mn and S signals found in Line Profile 1 is not observed. In this case, however, $\mathrm{S}$ is observed to extend 100-150 $\mathrm{nm}$ beyond the Mn on either side of the inclusion. This suggests the presence of a sulfur-rich interface between the inclusion and the bulk ferrite phase. It is clear that the $S$ content in the immediate surroundings of the inclusion is not exclusively associated with Mn. The solubility of S (as FeS) in an Mn-containing ferrite phase is extremely limited, and its presence is typically the result of a rapid quenching of the steel. This leads to the presence of FeS in the immediate surroundings of a "MnS" inclusion as well as the presence of Fe as a solid solution in the "MnS" lattice [28]. 


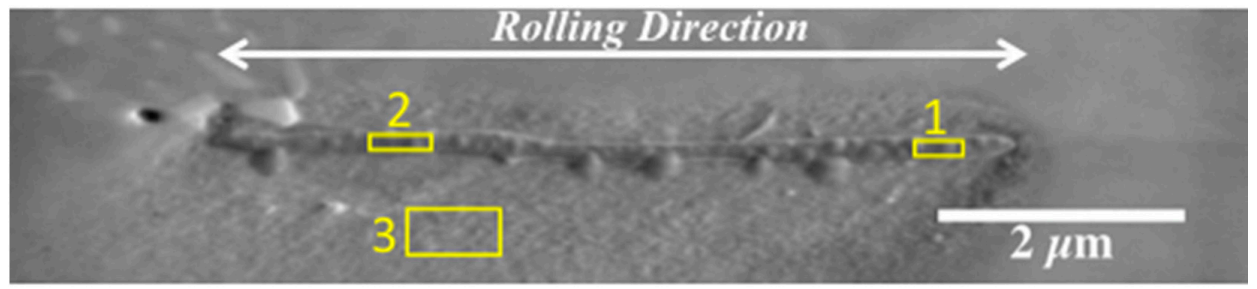

Auger Spectrum Region I

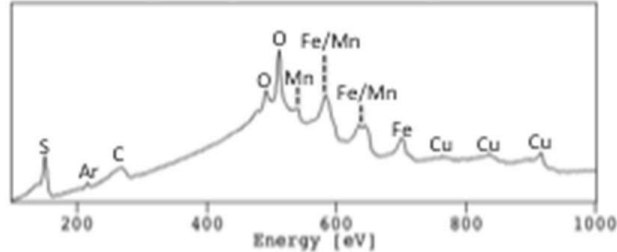

Auger Spectrum Region 2

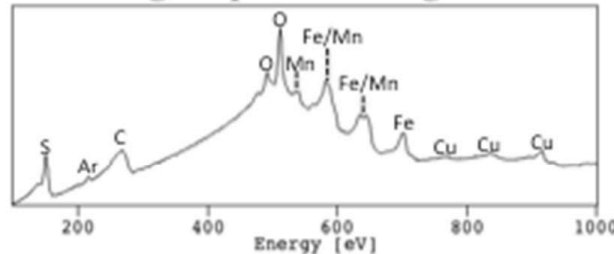

Auger Spectrum Region 3

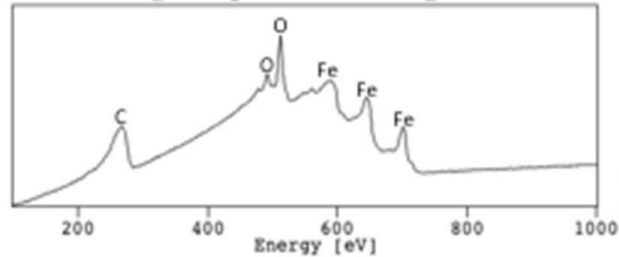

EDX Spectrum Region I

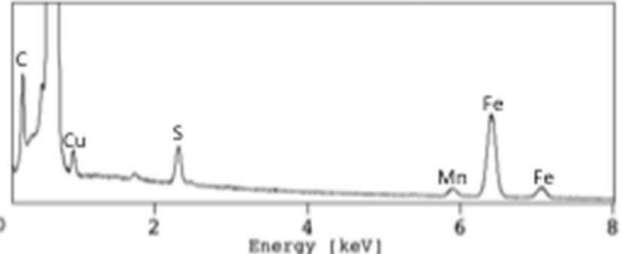

EDX Spectrum Region 2

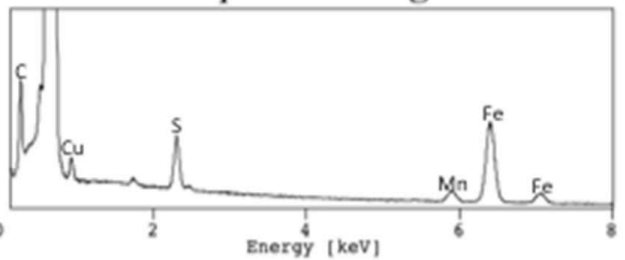

EDX Spectrum Region 3

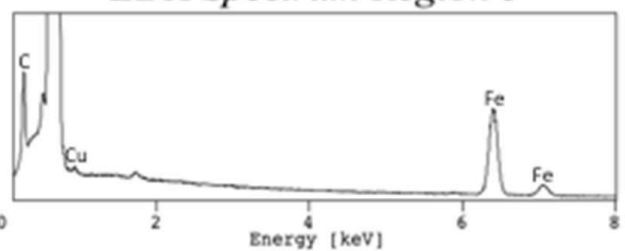

Figure 2. SEM image of MnS inclusion cut parallel to the rolling direction of the steel (top). Auger and EDX spectra (bottom) taken from the regions marked as 1, 2, and 3 in the SEM image.
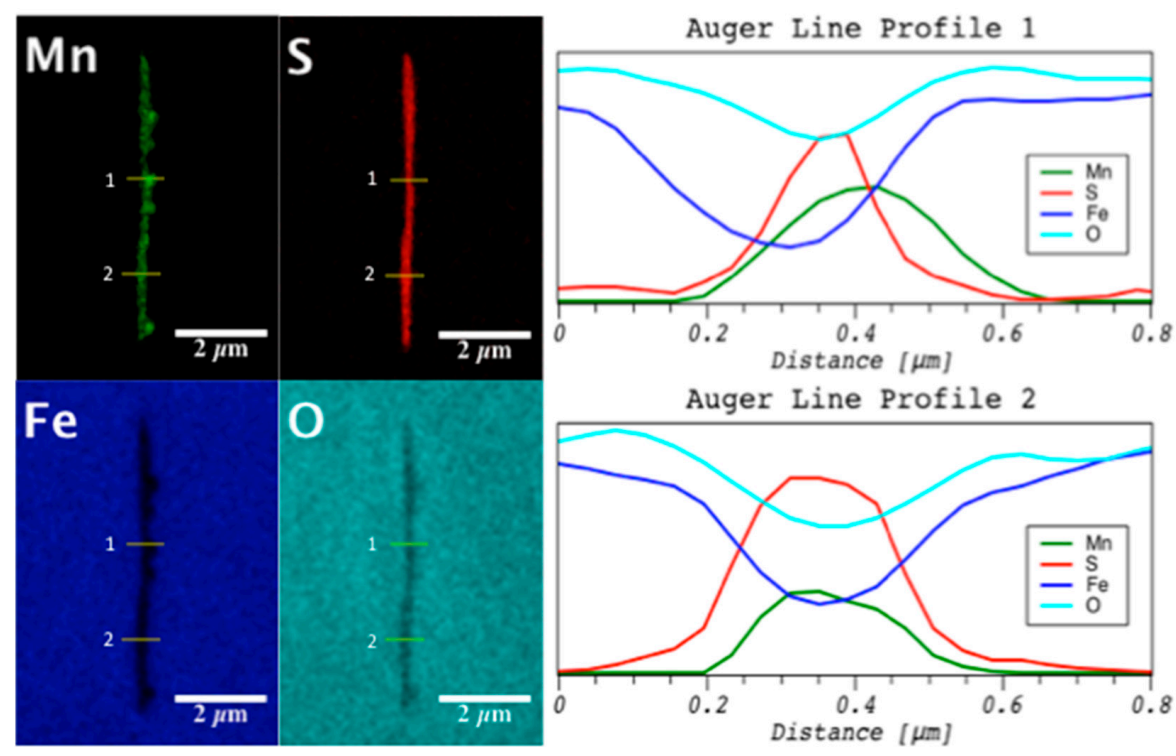

Auger Line Profile 2

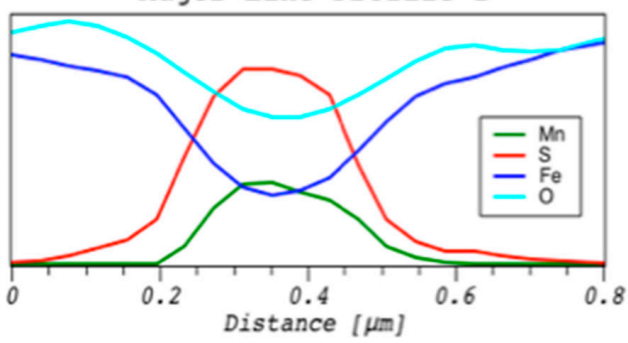

Figure 3. (Left) Auger elemental maps of Mn, S, Fe, and $\mathrm{O}$ taken from the area of the inclusion shown in Figure 2. Marked on the Auger maps are two horizontal lines (1 and 2) marking the locations of Auger line profiles 1 and 2. (Right) The Auger line profiles (from left to right) of $\mathrm{Mn}, \mathrm{S}, \mathrm{Fe}$, and $\mathrm{O}$ across the inclusion at the locations marked as 1 and 2. 
Shown in Figure 4 are a high-magnification SEM image and corresponding Mn, S, O, and Fe Auger elemental maps of a small region within an inclusion that exhibits nodular morphology. Note that these nodules, similar to that in Figure 3, Line Profile 1, are depleted in $S$ and that they contain relatively large amounts of oxygen along with manganese. Oxygen was still seen in Auger spectra taken from the inclusion even after extensive sputtering $(>10 \mathrm{~nm})$. Thus, the oxygen content seen in the nodules appears to be native to the inclusion as manganese oxide.

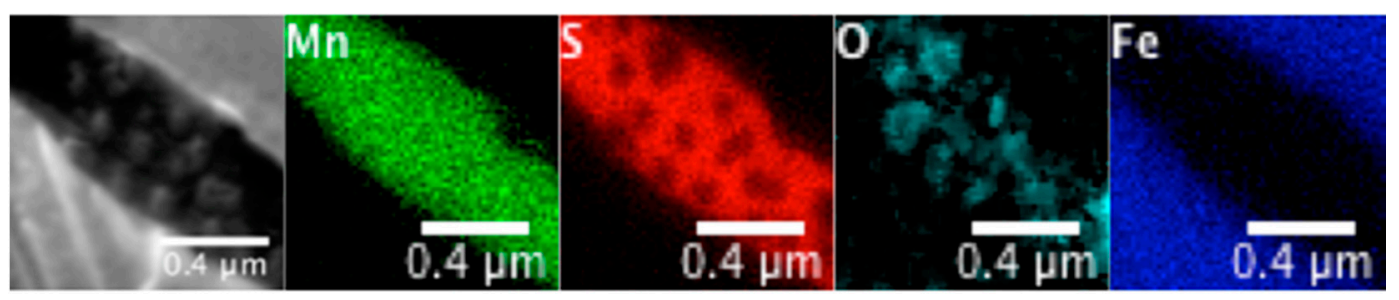

Figure 4. High-magnification SEM image and the Mn, S, O, and Fe Auger elemental maps taken from the SEM image of the MnS inclusion on the left.

The presence of oxygen within inclusions is seldom discussed in the literature, and it is of interest to discern whether the oxygen peaks seen in the Auger spectra are restricted to the surface as a metal oxide or are a component of the bulk "MnS" inclusion. To investigate this matter, Auger depth profiles were performed on one of the inclusions from a 1018 carbon steel sample cut perpendicular to the rolling direction while the $\mathrm{Fe}, \mathrm{S}, \mathrm{Mn}$, and $\mathrm{O}$ Auger signals were monitored as a function of depth; the results are shown in Figure 5. The full lines are data obtained from within the inclusion (Region 1), while the dashed lines are data collected from the neighboring ferrite phase (Region 2). The $\mathrm{O}$ signal on the ferrite phase (Region 2) rapidly decreases and gives an estimated thickness of about $8 \mathrm{~nm}$, in good agreement with typically reported values of native oxide thicknesses [29]. This is in contrast to the inclusion (Region 1 ), in which the $\mathrm{O}$ signal profile is significantly broader and persists after roughly $20 \mathrm{~nm}$ of sputtering. On some inclusions, the presence of excess $O$ persists up to $50 \mathrm{~nm}$ of sputtering (see Figure 6). The decrease in the $\mathrm{O}$ signal within the inclusion is associated with a rise in the S signal, while both the Mn and Fe signals remain relatively unchanged. This indicates a one-for-one replacement of $O$ with $S$, as is common amongst metal sulfides. Both $\mathrm{MnO}$ and $\mathrm{MnS}$ are isometric, with lattice parameters differing by approximately 15\% [30]; thus, it is reasonable to suggest that the O observed within the inclusion occupies $\mathrm{S}$ vacancies and that the diffusion of $\mathrm{O}$ within the inclusion occurs via hopping to neighboring $\mathrm{S}$ vacancies. The occupation of $\mathrm{S}$ vacancies by oxygen has been previously reported [31]. Such changes in stoichiometry will affect the electrical conductivity [32], as well as the electrochemical properties [33] of the inclusion, which is an intrinsic semiconductor. The Auger depth profile, seen in Figure 5, reveals that some surface regions of "MnS" inclusions are stable as the $\mathrm{MnO}$ phase, while approximately $25-30 \mathrm{~nm}$ below the inclusion surface, the bulk composition of "MnS" inclusions in atomic percentages appears to be $5-7 \% \mathrm{Fe}$ and $\mathrm{O}, 45-47 \% \mathrm{Mn}$ and S. 


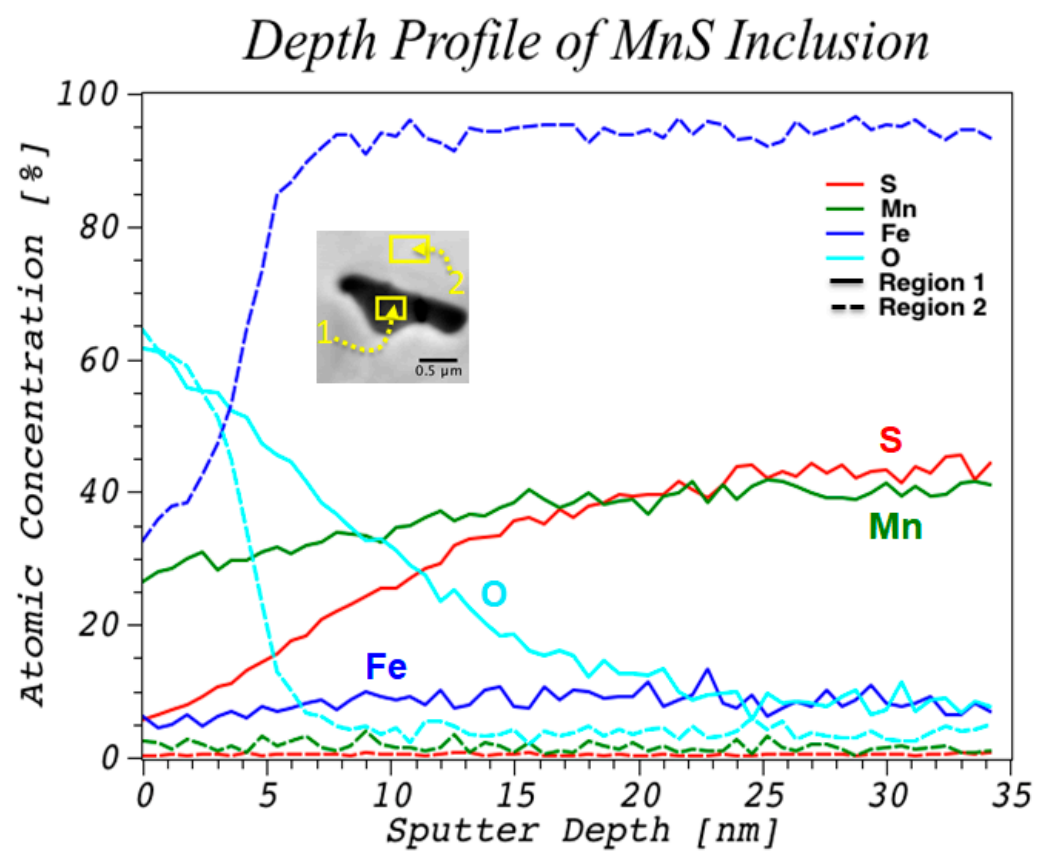

Figure 5. Auger depth profiles of $\mathrm{S}, \mathrm{Mn}, \mathrm{Fe}$, and $\mathrm{O}$ taken from regions marked as yellow squares labeled as Region 1 and Region 2 on the SEM image of the MnS inclusion shown in the inset. The inclusion was cut and polished perpendicular to the rolling direction of the steel. Region 1 corresponds to an area on the inclusion, while region 2 corresponds to a ferrite grain outside the MnS inclusion.

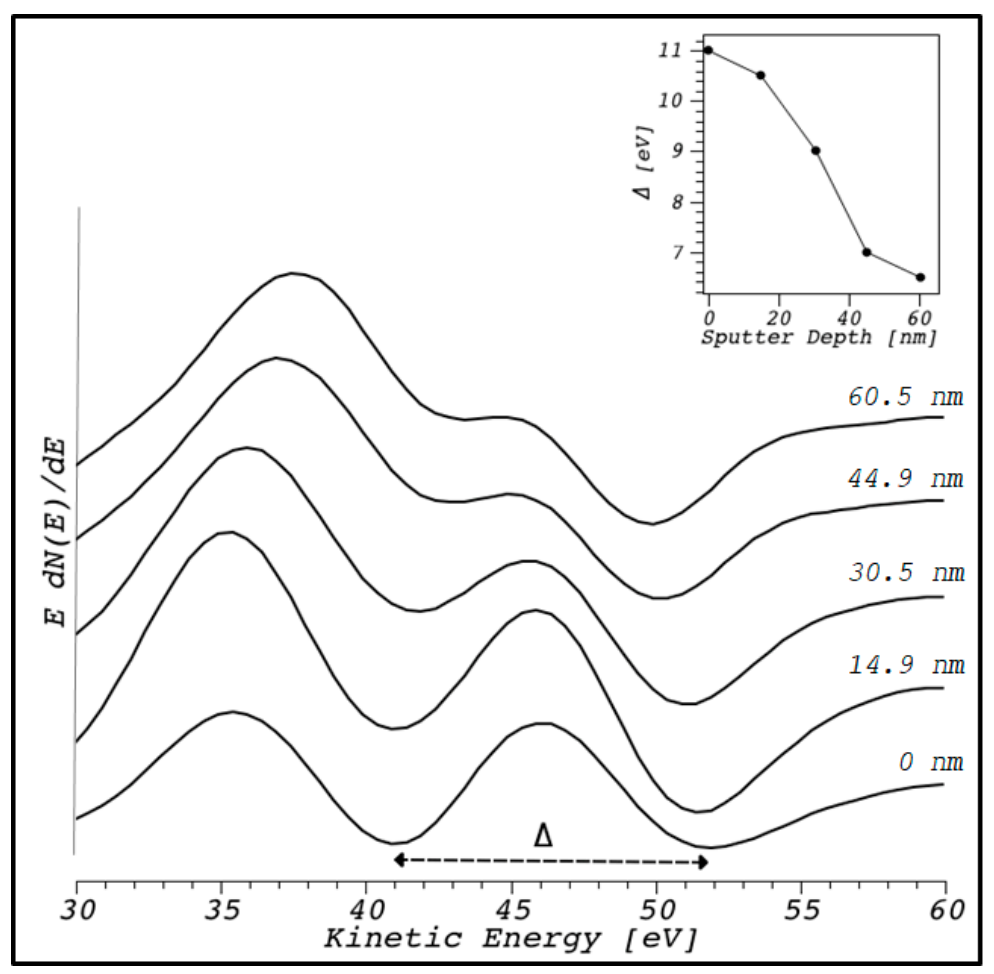

Figure 6. Depth profiles acquired from a thick MnO film grown on an MnS inclusion. The differentiated Mn MVV Auger spectrum is shown at select depths below the surface. The quantity $\Delta$ indicates the energy separation between the two minima of the differentiated Auger spectrum associated with the Mn MVV Auger transition. This split is greatest if Mn is associated with O instead of S. Such splitting enables Auger to achieve chemical mapping as shown in Figure 7. The inset (top right) shows the variation of $\Delta$ as a function of depth. 

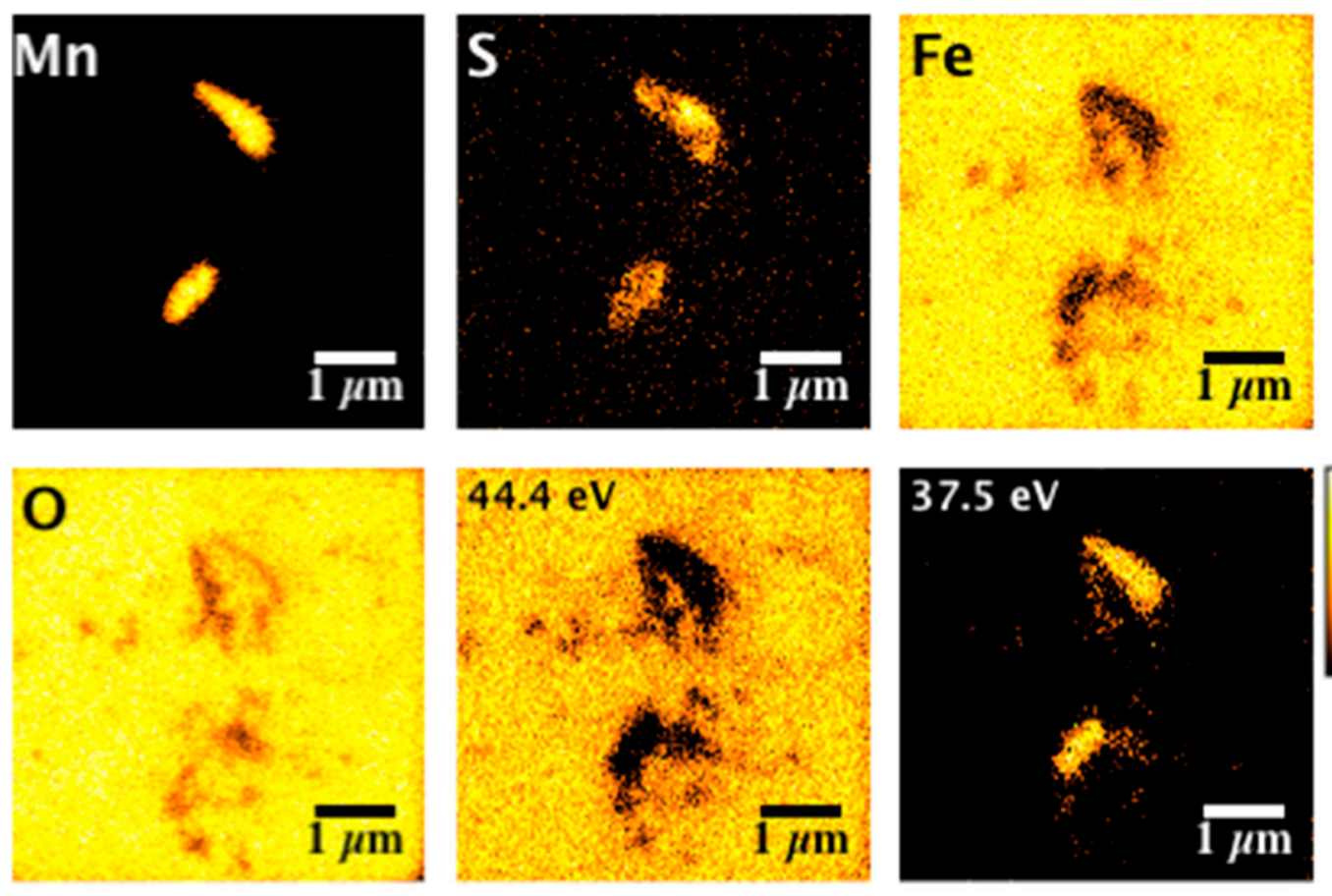

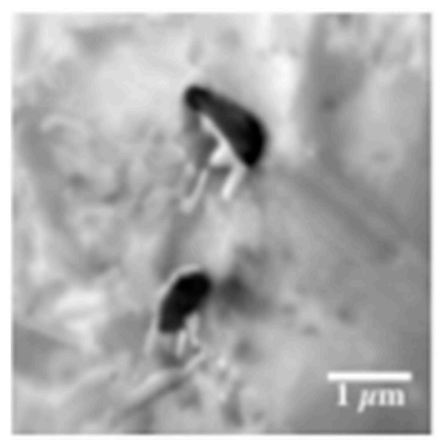

Figure 7. $\mathrm{Mn}, \mathrm{S}, \mathrm{Fe}, \mathrm{O}, \mathrm{FeO}$, and $\mathrm{MnO}$ Auger maps from a region of $\mathrm{MnS}$ inclusion cut perpendicular to the rolling direction of the steel. The images labeled as $\mathrm{Mn}, \mathrm{S}, \mathrm{Fe}$, and $\mathrm{O}$ represent maps of these elements, and the $44.4 \mathrm{and} 37.5 \mathrm{eV}$ maps correspond to $\mathrm{FeO}$ and $\mathrm{MnO}$, respectively. The SEM image of the inclusions is shown in the lower left panel.

Auger transitions involving valence band electrons are highly sensitive to the local chemical environment [34]. Additionally, because of their relatively low kinetic energy (approximately $50 \mathrm{eV}$ ), they are more sensitive to the surface composition than the corresponding higher-energy Auger transitions. Shown in Figure 6 are Mn MVV derivative spectra collected at various depths below the surface of an "MnS" inclusion. The nominal value of the metallic Mn MVV Auger transition is $45 \mathrm{eV}$ [35]. When present as an oxide or sulfide, the peak at $45 \mathrm{eV}$ is split into two peaks. The difference in energy between the two peaks, marked as $\Delta$ in Figure 6 , can be used to assess the chemical state of Mn within the inclusion. The inset in Figure 6 shows $\Delta$ as a function of depth, which is observed to decrease from a value of 11.0 to $6.5 \mathrm{eV}$. MnO formation on MnS surfaces was verified with a surface analysis of MnS powder purchased from Sigma Aldrich (St. Louis, MO, USA). The particles of MnS powder built a thick (approximately $390 \mathrm{~nm}$ ) MnO layer (presumably formed during the shelf life of the MnS powder), which was removed by Ar-ion sputtering to reach the pure $\mathrm{MnS}$ phase. The initial value of $\Delta=11.0 \mathrm{eV}$ from the inclusion agrees well with the reference spectrum from oxidized $\mathrm{MnS}$ powder. As seen in Figure 6, $\Delta$ decreases to a value of $6.5 \mathrm{eV}$ at a depth of $60.5 \mathrm{~nm}$, which is in good agreement with reference spectra taken from sputter-cleaned MnS powder. The question arises of how to account for the residual 5-7\% Fe and O observed in the bulk "MnS." We hypothesize that during 
the metallurgical preparation of the steel, Fe resides in solid solution in MnS inclusions, a fairly well established fact [28]. Furthermore, we hypothesize that the MnS inclusions are nonstoichiometric and contain $S$ vacancies. As mentioned above, these vacancies may accommodate $\mathrm{O}$ atoms. The thick oxide layer observed in the depth profiles shown in Figures 5 and 6 are a result of $O$ diffusion within the bulk inclusion via these vacancies. Thus, we believe the correct formulation of the composition of MnS inclusions may be written as $\mathrm{Mn}_{(1-x)} \mathrm{Fe}_{\mathrm{x}} \mathrm{S}_{(1-\mathrm{y})} \mathrm{O}_{\mathrm{y}}$. Given that the observed Fe signal remains constant through the depth profile on the inclusion (Figure 5), the value of $x$ is not expected to vary significantly through the depth of the inclusion. In contrast, the $\mathrm{O}$ content (y) appears to vary considerably through the inclusion bulk, and in some cases across its surface (Figure 4). It is clear that upon exposure to air, some parts of the inclusions form a fairly thick $\mathrm{MnO}$ layer while other regions do not (Figure 4). It is not clear at this time why $\mathrm{MnO}$ grows on particular regions of "MnS" inclusions. We believe that the $\mathrm{MnO}$ on the surface of "MnS" inclusions is formed after the surface is exposed to air, perhaps while the surface is polished. From thermodynamical considerations (free energy of formations) it appears that $\mathrm{MnO}$ is favored over $\mathrm{MnS}$ at room temperatures [28]. These data show that the surface composition of these inclusions differs considerably from the bulk.

Shown in Figure 7 are Auger elemental and chemical maps collected with a primary beam energy of $5 \mathrm{keV}$ from a perpendicularly cut "MnS" inclusion. The $\mathrm{Mn}, \mathrm{S}$, and Fe Auger maps (Figure 7, first row) were collected using the Mn LMM (545 eV), S LMM (153 eV), and Fe LMM (705 eV) Auger transitions [35]. Similarly, the O Auger map (Figure 5, second row) was collected using the O KLL transition ( $510 \mathrm{eV}$ ) [35]. These transitions involve core level electrons and are fairly insensitive to the chemical environment of the atom. In Figure 7 (second row), we also show Auger maps of the low-energy MVV Auger transitions of Fe $(44.4 \mathrm{eV})$ and $\mathrm{Mn}(37.5 \mathrm{eV})$. Low kinetic energy Auger transitions involving valence band electrons are highly sensitive to the local chemical environment of the Fe and $\mathrm{Mn}$ atoms, and thus can be used to identify the chemical states of elements present on the surface [34]. The nominal value of the Fe MVV Auger transition from a non-oxidized surface is $50 \mathrm{eV} \mathrm{[35];}$ upon oxidation, this peak is split into two peaks [36]. For the map shown in Figure 7, the peak at $44.4 \mathrm{eV}$ was used to identify Fe present in the native oxide formed on the steel surface. The peak at $37.5 \mathrm{eV}$ was used to identify $\mathrm{Mn}$ believed to be present as $\mathrm{MnO}$ (see Figure 6). All of the maps in Figure 7 were collected after sputtering about $0.5 \mathrm{~nm}$ of material from the surface with $500 \mathrm{eV} \mathrm{Ar}{ }^{+}$ions in order to remove exogenous hydrocarbons accumulated on the surface, which can significantly attenuate signals corresponding to low-energy (MVV) Auger transitions. The Fe LMM and O KLL Auger maps show that both are present on the steel as well as on the inclusion surfaces; however, the map taken at $44.4 \mathrm{eV}$ shows that the oxide on the inclusion surface is chemically distinct from the oxide present on the steel surface, and in particular that the oxygen observed on the inclusion is not associated with Fe. On the other hand, the Auger map taken using $37.5 \mathrm{eV}$ Auger electrons clearly reveals that the oxide present on the inclusions is solely associated with $\mathrm{Mn}$; it is believed to be MnO. The oxygen KLL Auger map in Figure 7 exhibits low-intensity features in the vicinity of both of the inclusions, suggesting thinning of the oxide film in this region. Spurious pixels in the $37.5 \mathrm{eV}$ map appear to be spatially correlated with these oxygen-depleted regions. Both the $\mathrm{Mn}$ and S Auger maps in Figure 7 show that the spurious pixels are absent in the oxygen-depleted regions. It is possible that these are related to the $\mathrm{Fe}$ in the native oxide layer and that the film in this region is physically distinct from that in other regions on the steel surface. This manifests itself as a shift in the Fe MVV peak and appears as an absence of Fe oxide in these regions.

Electron backscatter diffraction (EBSD) can be employed to determine the crystallographic orientation and phases of ordered crystals from submicron-size grains. We employed EBSD in the integrated Auger system to identify the crystal phases present within the "MnS" inclusions. From the Auger and EDX spectra, we confirmed the presence of $\mathrm{Fe}, \mathrm{Mn}, \mathrm{S}$, and $\mathrm{O}$ as typical constituents of the bulk structure of the "MnS" inclusions. We observed ordered domains on "MnS" inclusions and determined that these regions are 
FCC structures with space group SG225 having m3m point group symmetry. Similarly, we studied $\alpha$-Fe (ferrite) domains and identified them as BCC structures having $\mathrm{m} 3 \mathrm{~m}$ point group symmetry. Thus, it is reasonable to suggest the following phases are present within the inclusions and the surrounding bulk steel: $\alpha$-Fe (ferrite), MnS (alabandite), and $\mathrm{MnO}$ (manganosite).

Shown in the top panel of Figure 8 is a combined inverse pole figure (IPF) map of the $\mathrm{MnS}$ and $\mathrm{MnO}$ phases identified in the inclusion shown in Figure 2. Given the similarity of the Kikuchi patterns of the two crystalline structures, it was not possible to distinguish between the two phases with a reasonable degree of certainty. FeS, where identified, corresponded to a negligible fraction of the indexed points, primarily existing within grain boundaries. The presence of $\alpha$-Fe was not detected within the inclusion. Regions within the inclusion identified as $\mathrm{MnS} / \mathrm{MnO}$ are believed to be crystalline (FCC cubic MnS or $\mathrm{MnO}$ ), while areas not associated with these phases are believed to be highly disordered. The crystalline regions of the inclusion are not uniformly distributed: there is localized clustering along the length of the inclusion. Because of kinetic effects related to rapid cooling/quenching of the steel, loss of crystalline order may have occurred during the metallurgical preparation or the rolling of the steel. We note that the crystalline regions exhibit a strong texture oriented in the [101] direction, indicated by the color green in the top panel of Figure 8.
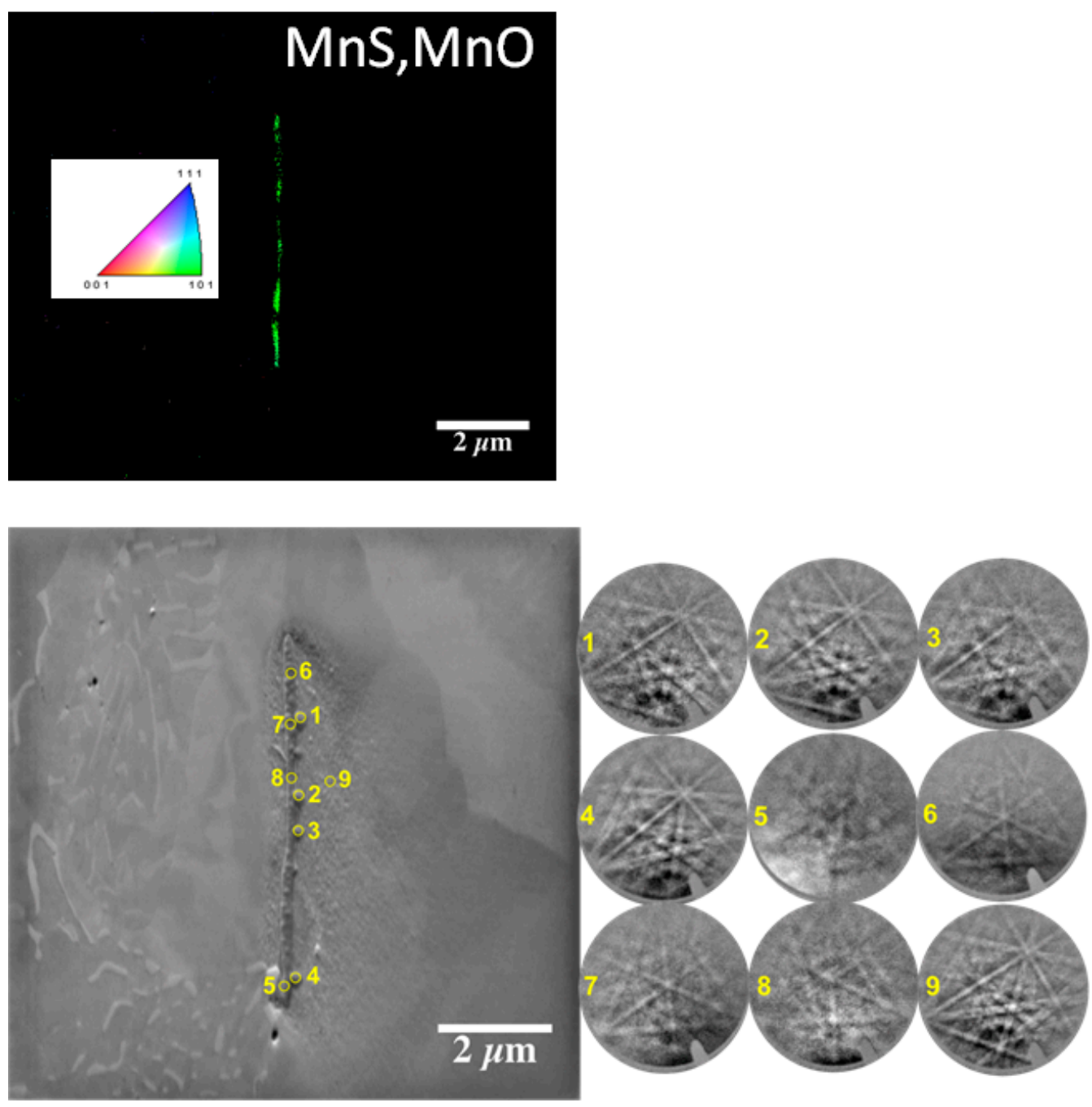

Figure 8. Top: Orientation image of the $\mathrm{MnS}$ and $\mathrm{MnO}$ phases. Both are FCC structures with m3m point group symmetry. The SEM image of the "MnS" inclusion is shown in the bottom left panel with numbers marking the locations where Kikuchi diffraction patterns were obtained; these are presented at the bottom right. 
The bottom panels in Figure 8 show Kikuchi patterns taken at various locations within the inclusion, marked on the SEM image shown on the left. There is marked variation in pattern quality in terms of band contrast throughout the inclusion. In particular, we note that regions 1-4, with nodular morphology (shown to be $\mathrm{MnO}$ ), and the ferrite phase (region 9) exhibit good pattern quality. These patterns all suggest FCC crystal structure with $\mathrm{m} 3 \mathrm{~m}$ point group symmetry on the inclusion and BCC on region 9 . This is in contrast to other regions within the inclusion (regions 5-8), in which the pattern quality varies from fair to poor.

As discussed above, the presence of $\mathrm{Cu}$ in most of the inclusions warrants further consideration. In particular, why $\mathrm{Cu}_{2} \mathrm{~S}$ films (verified by quantitative elemental analysis) coat "MnS" inclusions, but not Fe grains, requires further study. We observed $\mathrm{Cu}_{2} \mathrm{~S}$ phases coexisting with or independent from the "MnS" inclusions, which extend along the rolling direction of the steel. An example of this is shown in the inset of Figure 9, in which the little bright spot located on the $\mathrm{MnS}$ inclusion is the tip of a $\mathrm{Cu}_{2} \mathrm{~S}$ inclusion grown alongside the MnS stringer and extending perpendicular to the surface into the bulk. In addition to this $\mathrm{Cu}_{2} \mathrm{~S}$ phase, we also observe a thin layer of a $\mathrm{Cu}_{2} \mathrm{~S}$ film that is deposited on the surface of the "MnS" inclusion outside the $\mathrm{Cu}_{2} \mathrm{~S}$ (small bright dot) phase shown in Figure 7. Examples of such $\mathrm{Cu}_{2} \mathrm{~S}$ thin films were observed using surface-sensitive Auger spectroscopy as discussed above in Figure 2. Taking advantage of the high spatial resolution and surface sensitivity of the Auger nanoprobe, we conducted Auger depth profiles on several inclusions using Ar-ion sputtering while monitoring the $\mathrm{Cu}, \mathrm{Fe}, \mathrm{Mn}$, and S Auger signals. Figure 9 is an example of such work: the depth profile was conducted from the yellow square marked on the inclusion away from the actual $\mathrm{Cu}_{2} \mathrm{~S}$ stringer. From this, the estimated thickness of the $\mathrm{Cu}$ layer was determined to be approximately 5-6 $\mathrm{nm}$. This range of thicknesses of $\mathrm{Cu}_{2} \mathrm{~S}$ layers was commonly observed amongst the inclusions studied. We note that initially, the $\mathrm{Cu}$ and $\mathrm{S}$ signals increase together, whilst the Mn and Fe signals remain relatively unchanged. This seems to indicate that the $\mathrm{Cu}$ is present as a $\mathrm{Cu}_{2} \mathrm{~S}$ layer, determined by quantitative elemental analysis. Beyond this layer, the $\mathrm{S}$ signal continues to rise along with that of $\mathrm{Mn}$ until both stabilize. Because of its affinity for sulfur (i.e., chalcophilicity), the presence of $\mathrm{Cu}$ on the surface of sulfide inclusions is not surprising. However, we note that $\mathrm{Cu}_{2} \mathrm{~S}$ has a higher standard energy of formation than MnS [28]. We hypothesize that the formation of $\mathrm{Cu}_{2} \mathrm{~S}$ layer over an $\mathrm{MnS}$ inclusion is due to the surface energy of formation and involves surface-driven thermodynamic interactions.

\section{Depth Profile of MnS Inclusion}

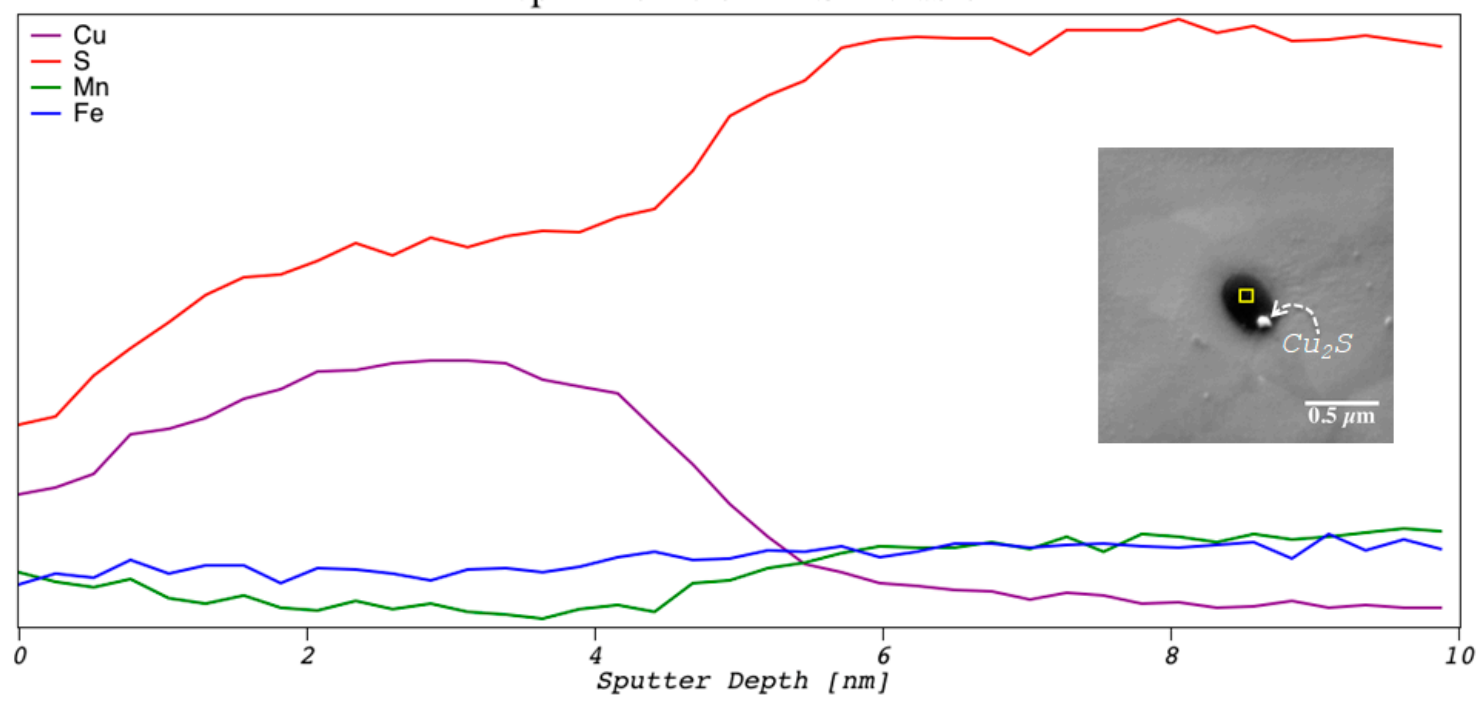

Figure 9. Auger depth profiles of $\mathrm{Cu}, \mathrm{S}, \mathrm{Mn}$, and Fe taken from the yellow square marked on a "MnS" inclusion (inset) cut perpendicular to the rolling direction of the steel. 
Others have observed the presence of $\mathrm{Cu}_{2} \mathrm{~S}$ on $\mathrm{MnS}$ inclusions in stainless steels after exposure to various corrosive environments [5,37-39]. In these references, it was suggested that dissolved $\mathrm{Cu}$-ions act to passivate some inclusions. In their studies, $\mathrm{Cu}_{2} \mathrm{~S}$ was not observed on the inclusions before exposure to corrosive media. This is most likely due to the use of non-surface-sensitive techniques, e.g., EDX using high primary beam energies $(>20 \mathrm{keV})$, which will miss the presence of a thin layer of $\mathrm{Cu}$ on the inclusion. The presence of a $\mathrm{Cu}_{2} \mathrm{~S}$ coating on some "MnS" inclusions may introduce a galvanic coupling with the surrounding bulk steel, making these regions of the surface more corrosively active, though we have no conclusive evidence to this effect in our studies. We note that some, but not all, inclusions characterized in this study exhibited a thin $\mathrm{Cu}_{2} \mathrm{~S}$ layer in their respective Auger spectra. Admittedly, we wondered what the source of a $\mathrm{Cu}_{2} \mathrm{~S}$ layer over an "MnS" inclusion might be. Our current hypothesis is that the source is most likely $\mathrm{Cu}_{2} \mathrm{~S}$ inclusions (stringers) distributed within the carbon steel matrix. For example, the bright spot located inside the "MnS" inclusion marked in the inset of Figure 9 is probably the source of the $\mathrm{Cu}_{2} \mathrm{~S}$ thin layer over the "MnS" surface. The observed thin $\mathrm{Cu}_{2} \mathrm{~S}$ layer is likely a result of sample preparation (i.e., cutting and polishing): as various coupons are cut from the same bar of steel, the released $\mathrm{Cu}_{2} \mathrm{~S}$ moieties preferentially find their way onto the "MnS" inclusions, forming a thin (approximately $5 \mathrm{~nm}$ ) nanolayer of $\mathrm{Cu}_{2} \mathrm{~S}$. We have documented in a thesis [40] and in our recent TEM analysis that it is the residual plastic strain and the subsequent dislocations and lattice defects introduced into the nanoscale regions between the "MnS" inclusions and the host lattice that lead to initial localized corrosion and galvanic coupling between these interfaces $[14,40]$. The interface between the immediate surroundings of "MnS" inclusions and the unstrained host Fe grains leads to the initialization and growth of localized pits, as shown in Figure 10. We hypothesize that this is due to the mechanochemical effect [41], whereby efficient galvanic couples are formed between strained and unstrained regions of a steel surface, as modeled in Figure 10A [21]. This leads to localized pitting in the immediate surroundings of the inclusions and other strained Fe phases such as ferrite phases in pearlite lamella $[14,15]$. Corrosion along the rolling direction of MnS inclusions causes micropits (Figure 10B), which then coalesce with other micropits, giving rise to larger pits, and so on.

A comprehensive analysis of the interfaces between the "MnS" inclusions and the host metal using high-resolution transmission electron microscopy (TEM) is necessary to further document the relation between the initiation/growth of pits and the material properties of these localized regions at the nanoscale. We have prepared thin sections of these interfaces using a focused ion beam and obtained high-resolution TEM images and selected area diffraction data from these interfaces. These data are currently being analyzed and will be submitted for publication in the near future.

Because of the annealing and cold rolling treatments, the carbon steel surface contains a high density of areas with plastic strain, dislocations, MnS stringers, pearlite phases, and lattice defects. Assuming that the interfaces between inclusions and the host lattice in carbon steel are highly strained and heterogeneous, having FeS moieties in the narrow interface between the $\alpha$-Fe and the "MnS" inclusions will make these areas highly susceptible to the initiation of corrosion. It is anticipated that there will be a strong correlation between the rate of corrosion and the degree of strain in these areas. No pitting is expected on pure Fe surfaces, except in zones strained by local inclusions and at grain boundaries [14]. We hypothesize that the major pitting corrosion in 1018 carbon steel will be correlated with the immediate surroundings of MnS inclusions. This is because of the galvanic coupling modeled in Figure 10A leading to localized pitting in the immediate surroundings of inclusions, as shown in Figure 10B. There are two reasons for this: (1) the presence of unstrained Fe grains leading to galvanic coupling and (2) MnS dissolution in acidic environments generating highly corrosive products such as elemental $\mathrm{S}$ or $\mathrm{H}_{2} \mathrm{~S}$ which will participate in cathodic reactions on the Fe sides of the surface along the long $\mathrm{MnS}$ stringers. The hydrolysis of Fe ions in the immediate surroundings of $\mathrm{MnS}$ inclusions via $\mathrm{Fe}^{2+}+2 \mathrm{H}_{2} \mathrm{O} \rightarrow \mathrm{Fe}(\mathrm{OH})_{2}+2 \mathrm{H}^{+}$acidifies the local area. Under 
low-pH conditions $(\mathrm{pH}<4) \mathrm{MnS}$ starts dissolving via $\mathrm{MnS}+2 \mathrm{H}^{+} \rightarrow \mathrm{H}_{2} \mathrm{~S}+\mathrm{Mn}$, generating abiotic $\mathrm{H}_{2} \mathrm{~S}$ along the $\mathrm{MnS}$ inclusions (stringers), which extend hundreds of microns into the carbon steel matrix along the rolling direction while their width is $1 \mu \mathrm{m}$ or less. Typically, there are $3500 \mathrm{MnS}$ inclusions per $\mathrm{mm}^{2}$ area of carbon steel and the average distance between them is approximately $14 \mu \mathrm{m}[14,42]$. The abiotically created $\mathrm{H}_{2} \mathrm{~S}$ species react with the carbon steel surface and contribute to its dissolution through the reaction $2 \mathrm{H}_{2} \mathrm{~S}+\mathrm{Fe}^{0} \rightarrow 2 \mathrm{HS}^{-}+\mathrm{H}_{2}+\mathrm{Fe}^{2+}$, generating $\mathrm{H}_{2}$ gas in the process. Corrosion along the $\mathrm{MnS}$ inclusion causes micropits (Figure 10B), which then coalesce with other micropits, giving rise to larger pits, and so on.

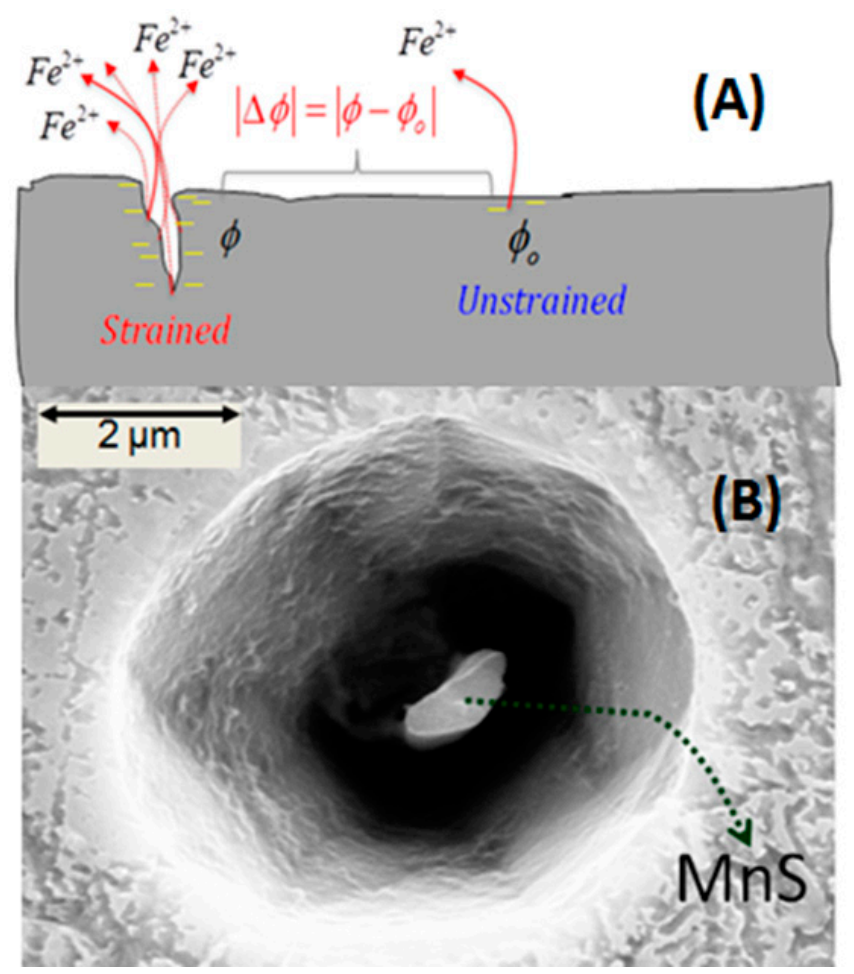

Figure 10. (A) Schematic of the mechanochemical effect in the corrosion of metals: an electrochemical potential difference (localized galvanic coupling) of $\Delta \phi=\phi-\phi_{0}$ is formed naturally where $\phi$ and $\phi_{0}$ correspond to the localized potentials in strained and unstrained areas of the steel, respectively. In strained areas, excess dissolution of $\mathrm{Fe}^{+2}$ ions leaves excess electrons in the steel, making these areas more negative relative to the unstrained areas of the ferrite grain, where low-level generalized corrosion is taking place. (B) Initiation and growth of a corrosion pit around a MnS inclusion on a polished 1018 carbon steel surface.

As shown in Figure 1, there are a large variety of inclusions found in carbon steels, many of them not metal sulfides. The interfaces between these inclusions and the host ferrite matrix will also possess a large degree of disorder and residual strain. Thus, the empirical fact that MnS inclusions are the known sites for pit initiation and growth cannot purely be explained on the basis of strain alone. The composition of the inclusion, in particular the presence of $S$, is highly relevant for sustained pit growth. Our work has shown that both the surface and bulk composition of MnS inclusions are highly heterogeneous, particularly with regard to $S$ content. Such variations in $S$ are expected to affect the pit growth kinetics as described above. Moreover, the electrochemical behavior of "MnS" inclusions may critically depend upon the surface composition. We may envision these inclusions as being doped by the presence of $\mathrm{Fe}$ and $\mathrm{O}$ and hypothesize that the degree of this doping is a distinguishing factor in whether an MnS inclusion forms the site for stable pit growth or not. 


\section{Conclusions}

Using a surface-sensitive integrated Auger nanoprobe, we have been able to demonstrate the complexity and heterogeneity of MnS inclusions.

1. The "MnS" inclusions have compositions on their surface that are different from that of the bulk. After the removal of 20-60 nm of the inclusion surface, the bulk atomic composition is approximately $42-45 \% \mathrm{Mn}$ and $7-8 \% \mathrm{Fe}, 45-46 \% \mathrm{~S}$ and $5-6 \% \mathrm{O}$. We believe the $\mathrm{Fe}$ is in solid solution, substituting in Mn sites in the MnS structure. We do not know exactly how $\mathrm{O}$ atoms are incorporated into the bulk structure of "MnS" inclusions, but we hypothesize that $\mathrm{O}$ atoms are in solution in the MnS lattice, replacing $S$ vacancies.

2. The surface compositions of "MnS" inclusions are not all the same: certain locations on the "MnS" surface are covered with a thick $(>20 \mathrm{~nm})$ layer of $\mathrm{MnO}$ film hypothesized to have formed during the cutting, polishing, and shelf life of the steel coupon. The thickness of the native Fe-oxide film on the ferrite grains is about $5 \mathrm{~nm}$. The $\mathrm{MnO}$ film on "MnS" inclusion is much thicker (>20 nm). This general behavior of $\mathrm{MnO}$ on "MnS" formations is confirmed with the Auger analysis of pure MnS powders purchased commercially, on which we observed MnO films as thick as $350 \mathrm{~nm}$.

3. The surfaces of some of the "MnS" inclusions are covered by an approximately 5$\mathrm{nm}$-thick $\mathrm{Cu}_{2} \mathrm{~S}$ film, hypothesized to have formed during the cutting and polishing process. Many " $\mathrm{MnS}$ " inclusions coexist with other inclusions, such as $\mathrm{Cu}_{2} \mathrm{~S}$ or TiN; $\mathrm{Cu}_{2} \mathrm{~S}$ stringers also stretch $100 \mathrm{~s}$ of microns along the rolling direction of the steel.

4. In some inclusions or in certain parts of a given inclusion, the $S$ map across the thin stringer extends beyond the "MnS" phase into the interfaces between the "MnS" inclusion and the bulk steel; in these cases, the $S$ is most likely associated with FeS adjacent to the "MnS" inclusion, which we believe contributes to the initial localized corrosion.

5. EBSD analysis of the "MnS" inclusions suggests that those inclusions that are crystalline have a cubic FCC structure with $3 \mathrm{~m} 3$ symmetry. Though it was challenging to differentiate these structures from the $\mathrm{MnO}$ structure using Kikuchi patterns, the elemental composition of the "MnS" surface distinguishes the oxide-rich regions from the S-rich regions. Many areas of "MnS" inclusions were disordered.

6. We hypothesize that the sites of pit initiation can be explained in terms of the electrochemical potential differences due to the mechano-chemical effect [41] established between unstrained ferrite iron, $\alpha-\mathrm{Fe}$, and the lattice defects, dislocations, and mismatches found at interfaces formed between $\alpha$-Fe and secondary phases such as the "MnS" inclusions, cementite phases, and grain boundaries distributed throughout carbon steel. We propose that the sites for pit growth and the distinction between active and passive "MnS" inclusions suggested by Wranglen [17] are due to the inhomogeneities of MnS inclusions described in this work. In particular, we expect that the variations in the $\mathrm{S}$ and $\mathrm{O}$ content of inclusion surfaces will alter the dissolution kinetics during pit growth in two ways: First, the availability of $S$ on the inclusion surface and within the bulk will limit the production of $\mathrm{H}_{2} \mathrm{~S}$, which in turn will limit the availability of cathodic reactants required for sustained rapid dissolution. Thus, it is expected that inclusions with a higher $\mathrm{S}$ content will be more corrosively active. Second, the equilibrium electrochemical potential of the inclusion will also depend on its surface composition. Variations in the equilibrium electrochemical potential will also result in variations in the local dissolution kinetics. The dependence of the inclusion surface composition on its electrochemical behavior is not straightforward, and further investigation in this regard is warranted. 
Author Contributions: Conceptualization, R.A.; methodology, R.A.; software, N.R., M.N.; formal analysis, N.R.; investigation, R.A., N.R., M.N.; resources, R.A.; data curation, N.R., M.N.; writingoriginal draft preparation, R.A., N.R., M.N.; writing-review and editing, R.A., N.R., D.M.; visualization, N.R.; supervision, R.A.; project administration, R.A.; funding acquisition, R.A., D.M. All authors have read and agreed to the published version of the manuscript.

Funding: This work is supported in part by NSF/NNCI grant ECCS1542210 and in part by ONR/MURI grant N00014-10-1-0946. The work is also supported in part by Montana State University funds supporting the Imaging and Chemical Analysis Laboratory (ICAL).

Institutional Review Board Statement: This study did not involve the use of animals or humans as test subjects.

Informed Consent Statement: This study did not involve the use of animals or humans as test subjects.

Data Availability Statement: The raw and processed data are available upon reasonable request.

Acknowledgments: The authors would like to thank I. Beech of Montana State University for valuable discussions regarding the localized corrosion of carbon steel, B. Davis and E. Roehm for contributions to some of the SEM-related work and L. Avci for her copy editing.

Conflicts of Interest: The authors declare no conflict of interest.

\section{References}

1. Tronstad, L.; Sejersted, J. The Effect of Sulphur and Phosphorus on the Corrosion of Iron. J. Iron Steel Inst. 1933, $127,425$.

2. Szklarska-Smialowska, Z. Influence of Sulfide Inclusions on the Pitting Corrosion of Steels. Corrosion 1972, 28, 388-396. [CrossRef]

3. Chiba, A.; Muto, I.; Sugawara, Y.; Hara, N. Microelectrochemical Investigation of Pit Initiation and Selective Dissolution between MnS and Stainless Steel. ECS Trans. 2013, 50, 15-23. [CrossRef]

4. Webb, E.G.; Suter, T.; Alkire, R.C. Microelectrochemical measurements of the dissolution of single MnS inclusions, and the prediction of the critical conditions for pit initiation on stainless steel. J. Electrochem. Soc. 2001, 148, B186-B195. [CrossRef]

5. Ke, R.R.; Alkire, R. Initiation of corrosion pits at inclusions on 304 stainless steel. J. Electrochem. Soc. 1995, 142, 4056-4062. [CrossRef]

6. Eklund, G.S. Initiation of Pitting at Sulfide Inclusions in Stainless Steel. J. Electrochem. Soc. 1974, 121, 467. [CrossRef]

7. Chiba, A.; Muto, I.; Sugawara, Y.; Hara, N. Pit Initiation Mechanism at MnS Inclusions in Stainless Steel: Synergistic Effect of Elemental Sulfur and Chloride Ions. J. Electrochem. Soc. 2013, 160, C511-C520. [CrossRef]

8. Castle, J.E.; Ke, R. Studies by Auger-Spectroscopy of Pit Initiation At the Site of Inclusions in Stainless-Steel. Corros. Sci. 1990, 30, 409-428. [CrossRef]

9. Baker, M.A.; Castle, J.E. The initiation of pitting corrosion at MnS inclusions. Corros. Sci. 1993, 34, 667-682. [CrossRef]

10. Ryan, M.P.; Williams, D.E.; Chater, R.J.; Hutton, B.M.; McPhail, D.S. Why stainless steel corrodes. Nature 2002, $415,770-774$. [CrossRef] [PubMed]

11. Frankel, G.S. Pitting Corrosion of Metals. J. Electrochem. Soc. 1998, 145, 2186. [CrossRef]

12. Frankel, G.S.; Li, T.; Scully, J.R. Perspective-Localized Corrosion: Passive Film Breakdown vs Pit Growth Stability. J. Electrochem. Soc. 2017, 164, C180-C181. [CrossRef]

13. Maurice, V.; Marcus, P. Progress in corrosion science at atomic and nanometric scales. Prog. Mater. Sci. 2018, 95, 132-171. [CrossRef]

14. Avci, R.; Davis, B.H.; Rieders, N.; Lucas, K.; Nandasiri, M.; Mogk, D. Role of Metallurgy in the Localized Corrosion of Carbon Steel. J. Miner. Mater. Charact. Eng. 2018, 6, 618-646. [CrossRef]

15. Avci, R.; Davis, B.H.; Wolfenden, M.L.; Beech, I.B.; Lucas, K.; Paul, D. Mechanism of MnS-mediated pit initiation and propagation in carbon steel in an anaerobic sulfidogenic media. Corros. Sci. 2013, 76, 267-274. [CrossRef]

16. Hayden, S.C.; Chisholm, C.; Grudt, R.O.; Aguiar, J.A.; Mook, W.M.; Kotula, P.G.; Pilyugina, T.S.; Bufford, D.C.; Hattar, K.; Kucharski, T.J.; et al. Localized corrosion of low-carbon steel at the nanoscale. NPJ Mater. Degrad. 2019, 3. [CrossRef]

17. Wranglen, G. Pitting and Sulfide Inclusions in Steel. Corros. Sci. 1974, 14, 331-349. [CrossRef]

18. Wranglén, G. Review article on the influence of sulphide inclusions on the corrodibility of Fe and steel. Corros. Sci. 1969, 9, 585-602. [CrossRef]

19. Williams, D.E.; Zhu, Y.Y. Explanation for initiation of pitting corrosion of stainless steels at sulfide inclusions. J. Electrochem. Soc. 2000, 147, 1763-1766. [CrossRef]

20. Stewart, J.; Williams, D.E. The Initiation of Pitting Corrosion on Austenitic Stainless Steels: On the Role and Importance of Sulphide Inclusions. Corros. Sci. 1992, 33, 457-474. [CrossRef]

21. Avci, R.; Suflita, J.; Jenneman, G.; Hampton, D. Impact of Metallurgical Properties on Pitting Corrosion in a High-Pressure Seawater Injection Pipeline. In Failure Analysis of Microbiologically Influenced Corrosion; Eckert, R., Skovhus, T., Eds.; CRC Press: Boca Raton, FL, USA, 2021. 
22. Faraji, M.; Wilcox, D.P.; Thackray, R.; Howe, A.A.; Todd, I.; Tsakiropoulos, P. Quantitative Characterization of Inclusions in Continuously Cast High-Carbon Steel. Metall. Mater. Trans. B Process Metall. Mater. Process. Sci. 2015, 46, 2490-2502. [CrossRef]

23. Li, S.; Hihara, L.H. Identification of inclusions in carbon steels using micro-Raman spectroscopy. J. Raman Spectrosc. 2016. [CrossRef]

24. Goldstein, J.; Newbury, D.; Joy, D.; Lyman, C.; Echlin, P.; Lifshin, E.; Sawyer, L.; Michael, J. Scanning Electron Microscopy and Microanalysis, 3rd ed.; Springer: New York, NY, USA, 2003.

25. Briggs, D.; Grant, J. Surface Analysis by Auger and X-ray Photoelectron Spectroscopy; IM Publications and SurfaceSpectra Limited: West Sussex, UK, 2003; ISBN 1901019047.

26. Dwivedi, D.; Lepková, K.; Becker, T. Carbon steel corrosion: A review of key surface properties and characterization methods. RSC Adv. 2017, 7, 4580-4610. [CrossRef]

27. Field, D.P. Recent advances in the application of orientation imaging. Ultramicroscopy 1997, 67, 1-9. [CrossRef]

28. Kiessling, R.; Westman, C. Sulphide inclusions and synthetic sulphides of the (Mn,Me)S-type. J. Iron Steel Inst. 1966, 204, 377-379.

29. Suzuki, S.; Yanagihara, K.; Hirokawa, K. XPS study of oxides formed on the surface of high-purity iron exposed to air. Surf. Interface Anal. 2000, 30, 372-376. [CrossRef]

30. Available online: www.mindat.org (accessed on 1 March 2021).

31. Zhang, C.; Lin, Z.; Huang, C.; Zheng, B.; Li, Y.; Wang, J.; Deng, M.; Tang, S.; Du, Y. Surface Sulfur Vacancies Induced the Direct Growth of Mesoporous MnS Nanosheets on Three-Dimensional Reduced Graphene Oxide with Ultrahigh Capacity as Electrode Materials for Supercapacitors. ACS Appl. Energy Mater. 2019, 2, 6599-6607. [CrossRef]

32. Satoa, H.; Miharaa, T.; Furutaa, A.; Uedab, Y.; Namatamea, H.; Taniguchia, M. Electronic structure of MnY $(\mathrm{Y}=\mathrm{S}, \mathrm{Se}, \mathrm{Te}) \mathrm{Energy}$ (eV). J. Electron Spectros. Relat. Phenomena 1996, 78, 87-90. [CrossRef]

33. Zhao, L.; Yu, X.; Yu, J.; Zhou, Y.; Ehrlich, S.N.; Hu, Y.S.; Su, D.; Li, H.; Yang, X.Q.; Chen, L. Remarkably improved electrode performance of bulk MNS by forming a solid solution with FES-Understanding the Li storage mechanism. Adv. Funct. Mater. 2014, 24, 5557-5566. [CrossRef]

34. Seo, M.; Lumsden, J.B.; Staehle, R.W. An AES analysis of oxide films on iron. Surf. Sci. 1975, 50, 541-552. [CrossRef]

35. Childs, K.D.; Carlson, B.A.; LaVanier, L.A.; Moulder, J.F.; Paul, D.F.; Stickle, W.F.; Watson, D.G. Handbook of Auger Electron Spectroscopy, 3rd ed.; Physical Electronics Inc.: Chanhassen, MN, USA, 1995.

36. Weißmann, R.; Koschatzky, R.; Schnellhammer, W.; Müller, K. Some Aspects of Auger Electron Spectra of 3d Transition Metal Oxides. Appl. Phys. 1977, 13, 46. [CrossRef]

37. Mehrazi, S.; Moran, A.J.; Arnold, J.L.; Buchheit, R.G.; Lillard, R.S. The Electrochemistry of Copper Release from Stainless Steels and Its Role in Localized Corrosion. J. Electrochem. Soc. 2018, 165, C860-C868. [CrossRef]

38. Lillard, R.S.; Kashfipour, M.A.; Niu, W. Pit Propagation at the Boundary between Manganese Sulfide Inclusions and Austenitic Stainless Steel 303 and the Role of Copper. J. Electrochem. Soc. 2016, 163, C440-C451. [CrossRef]

39. Zhou, Y.T.; Zheng, S.J.; Zhang, B.; Ma, X.L. Atomic scale understanding of the interaction between alloying copper and MnS inclusions in stainless steels in $\mathrm{NaCl}$ electrolyte. Corros. Sci. 2016, 111, 414-421. [CrossRef]

40. Martin, J. Biocorrosion of 1018 Steel in Sulfide Rich Marine Environments; a Correlation between Strain and Corrosion Using Electron Backscatter Diffraction; Montana State University: Bozeman, MT, USA, 2014.

41. Gutman, E.M. Mechanochemistry of Solid Surfaces; World Scientific Publishing: Singapore, 1994.

42. Davis, B.H. Anaerobic Pitting Corrosion of Carbon Steel in Marine Sulfidogenic Environements; Montana State University: Bozeman, MT, USA, 2013. 